\title{
Functional evidence for continued alveolarisation in former preterms at school age?
}

\author{
Sophie Yammine ${ }^{1,2}$, Anne Schmidt ${ }^{1,2}$, Oliver Sutter ${ }^{2}$, Sotirios Fouzas ${ }^{3}$, \\ Florian Singer ${ }^{2,4}$, Urs Frey ${ }^{1}$ and Philipp Latzin ${ }^{1,2}$
}

Affiliations: 'University Children's Hospital of Basel (UKBB), Basel, Switzerland. ${ }^{2}$ Division of Respiratory Medicine, Department of Paediatrics, University Children's Hospital Bern, Bern, Switzerland. ${ }^{3}$ Paediatric Respiratory Unit, University Hospital of Patras, Patras, Greece. ${ }^{4}$ University Children's Hospital Zurich, Zurich, Switzerland.

Correspondence: Philipp Latzin, University Children's Hospital UKBB, Spitalstrasse 33, 1 Postfach, 4031 Basel, Switzerland.

E-mail: philipp.latzinđukbb.ch

ABSTRACT Prematurity is the most common disruptor of lung development. The aim of our study was to examine the function of the more vulnerable peripheral airways in former preterm children by multiplebreath washout (MBW) measurements.

86 school-aged children, born between 24 and 35 weeks of gestation and 49 term-born children performed nitrogen MBW. Lung clearance index (LCI), and slope III-derived Scond and Sacin were assessed as markers for global, convection-dependent and diffusion-convection-dependent ventilation inhomogeneity, respectively.

We analysed the data of 77 former preterm (mean (range) age 9.5 (7.2-12.8) years) and 46 term-born children (mean age 9.9 (6.0-15.9) years). LCI and Sacin did not differ between preterm and term-born children. Scond was significantly elevated in preterm compared to term-born participants (mean difference $\mathrm{z}$-score $1.74,95 \%$ CI $1.17-2.30 ; \mathrm{p}<0.001$ ), with $54 \%$ of former preterm children showing elevated Scond. In multivariable regression analysis Scond was significantly related only to gestational age $\left(\mathrm{R}^{2}=0.37\right)$.

Normal Sacin provides evidence for a functionally normal alveolar compartment, while elevated Scond indicates impaired function of more proximal conducting airways. Together, our findings support the concept of continued alveolarisation, albeit with "dysanaptic" lung growth in former preterm children.

@ERSpublications

Evidence for a prematurity-related dysanaptic lung growth in former preterm children http://ow.ly/RUXUl

Received: March 252015 | Accepted after revision: Aug 182015 | First published online: Oct 222015

Support statement: The work for this article was funded by the Swiss National Science Foundation (grant 324730_144280/1), Linde AG, the Gottfried and Julia Bangerter-Rhyner Foundation, a long-term fellowship of the German-Swiss-Austrian Society for Paediatric Pulmonology (GPP) (A. Schmidt) and Fondation Botnar. The funders had no role in study design, data collection and analysis, decision to publish or preparation of the manuscript. Funding information for this article has been deposited with FundRef.

Conflict of interest: None declared.

Copyright OERS 2016 


\section{Introduction}

On a global scale, the proportion of preterm births has increased steadily over the past decades [1]. Despite remarkable advances in neonatal and perinatal care [2], the incidence of bronchopulmonary dysplasia (BPD) remains high, affecting up to $40 \%$ of the extremely premature infants who survive [3, 4]. Since its first description almost 50 years ago [5], advances in the management of respiratory distress syndrome (prenatal steroids, administration of surfactant and the minimising of oxygen toxicity and barotrauma) have led to changes in the underlying pathological features of BPD. Thus, the contemporary form of the disease is characterised by impaired alveolar and vascular development which results in abnormal septation, fewer and larger alveoli and a smaller vascular bed, but with only minimal peribronchial fibrosis and airway muscle hypertrophy [6-8].

Despite the apparently less severe lung pathology in infants born extremely premature in the post-surfactant era, long-term respiratory impairment still exists. Several studies have shown evidence of airway obstruction [9-13] and air trapping [10, 12, 13] at school age in such populations. However, few studies have specifically examined ventilation inhomogeneity as a biomarker of peripheral lung function, and with inconclusive results. Two studies in preterm infants showed contradictory results, one with elevated ventilation inhomogeneity [14] and the other with no sign for ventilation inhomogeneity [15]. At school-age only one study examined ventilation inhomogeneity in former preterm children, showing mildly elevated ventilation inhomogeneity in 58\% of them [10]. Currently, BPD affects mainly premature infants born during the early saccular period of lung development. Thus, because the subsequent alveolar period of lung development is disrupted [16, 17], long-term adverse effects on lung function are not unexpected.

Therefore, the aim of our study was to examine the function of the most vulnerable peripheral lung regions in former preterm children at school age using multiple-breath washout (MBW) measurement, a well-established technique for the assessment of small airway function [18-21]. In addition to the lung clearance index (LCI) and moment ratios which were used as measures of global ventilation inhomogeneity, we particularly focused on specific parameters of regional ventilation inhomogeneity, namely Sacin for the alveolar lung regions and Scond for the conducting airways. We hypothesised that due to the premature disruption of normal lung development, former preterm children may present an abnormal ventilation distribution, particularly in alveolar lung regions.

\section{Methods}

Study population

Between February 2012 and June 2014, we prospectively recruited former preterm and term-born children aged 6-16 years at the University Children's Hospital Bern (Bern, Switzerland). Preterm-born participants ( $<37$ weeks of gestation) were recruited from a previously described study [22] and outpatient clinics. Preterm children with congenital bronchopulmonary malformations or thoracic-abdominal surgery were excluded. According to their gestational age, preterm children were classified into extremely low gestational age neonates (ELGAN) ( $<28$ weeks of gestation) or no-ELGAN ( $\geqslant 28$ weeks of gestation). Term-born controls with birth weight appropriate for gestational age (i.e. $>2500 \mathrm{~g}$ in all cases) were recruited from local schools and playgroups. Term-born children with asthma or other chronic respiratory diseases were excluded. Exclusion criteria for both preterm and term-born participants were respiratory infections within the last 3 weeks.

The study was approved by the ethics committee of the Canton Bern, Switzerland. The children's assent was obtained and parents or caregivers provided written informed consent.

\section{Assessment of respiratory symptoms and atopic sensitisation in former preterm participants}

In preterm children symptoms related to asthma and allergy were assessed by an adapted International Study of Asthma and Allergies in Childhood (ISAAC) questionnaire completed by the parents [23]. For later subgroup analysis, we focused on four binary outcomes (yes/no): wheeze over the past 12 months; cough without cold; shortness of breath due to cough or asthma; and doctor-diagnosed asthma. "Current asthma" was defined as wheeze or use of asthma medication in the past 12 months or doctor-diagnosed asthma. Atopic sensitisation was assessed by positive skin-prick testing on at least one common inhalant allergen (mixed trees, mixed grasses, cat, dog, house dust mite and Aspergillus fumigatus). We further measured the fraction of exhaled nitric oxide $(F$ eNO) by the single-breath method using a commercially available analyser (CLD 77 AM; Eco Medics AG, Duernten, Switzerland). After inhaling nitric oxide-free air to total lung capacity (TLC), children exhaled against an expiratory resistance with a constant flow of $50 \mathrm{~mL} \cdot \mathrm{s}^{-1}$ for $\geqslant 6 \mathrm{~s}$.

To prove the validity of our findings irrespective of other possible changes in lung development, we performed sensitivity analysis comparing three subgroups of preterm children to term-born controls: 1) absence of respiratory symptoms (absent if all four survey questions mentioned above were negative); 2) no current asthma; and 3) absence of atopic sensitisation (negative skin-prick testing and FeNO <20 ppb; [24]). 
Nitrogen multiple-breath washout

All children performed nitrogen $\mathrm{MBW}\left(\mathrm{N}_{2} \mathrm{MBW}\right)$ according to current consensus [25] using a previously described setup [26, 27] (Exhalyzer D; Eco Medics AG). The application of 100\% oxygen washes out the lung-resident nitrogen. The nitrogen signal is measured indirectly from oxygen, carbon dioxide and the estimated argon fraction. Children performed $\mathrm{N}_{2} \mathrm{MBW}$ while sitting upright, wearing a nose clip and tidally breathing through a snorkel mouth piece. At least two successful $\mathrm{N}_{2} \mathrm{MBW}$ runs were obtained. $\mathrm{N}_{2}$ MBW runs were accepted if functional residual capacity (FRC) varied $<10 \%$ for two and $<25 \%$ for three trials [25]. Measurements with leaks were excluded.

All data were recorded and analysed using Spiroware 3.1.6 (Eco Medics AG). Outcomes were calculated as currently recommended [25]; LCI from cumulative expired volume divided by FRC, resulting in lung turnover units. We used LCI and moment ratios $\left(\mathrm{M}_{1} / \mathrm{M}_{0}\right.$ and $\left.\mathrm{M}_{2} / \mathrm{M}_{0}\right)$ as a measure of global ventilation inhomogeneity. As specific markers for peripheral lung ventilation we analysed slopes of alveolar phase III (SIII) of the nitrogen expirogram. The first SIII value is thought to reflect ventilation inhomogeneity within diffusion-convection-dependent acinar airways (Sacin), while the subsequent evolution of SIII values from lung turnover 1.5 to 6.0 is thought to reflect ventilation inhomogeneity within convection-dependent conducting airways (Scond) [25]. Scond was calculated according to a validated automated algorithm with SIII determination between $65 \%$ and $95 \%$ of expired volume and exclusion of breaths deviating $>25 \%$ from median tidal volume with additional visual control of breath quality [28]. Breaths without a clear linear phase III portion of the expirogram, or irregular expiration and oscillation were excluded. SIII values were normalised for mean gas concentration over their calculation interval and corrected for tidal volume [29]. If insufficient SIII values were left, i.e. if $>33 \%$ of all SIII values were deselected, Scond was excluded [25]. In addition, we assessed minute ventilation and airway dead space volume $(V \mathrm{D})$ using FowLER's [30] method on the carbon dioxide expirogram of washout breaths.

\section{Spirometry}

Spirometry was performed only in former preterm children after washout measurements using the MasterLab setup (Jaeger, Wurzburg, Germany) and according to standard guidelines [31]. Forced expiratory volume in $1 \mathrm{~s}(\mathrm{FEV} 1)$ and forced expiratory flow at $25-75 \%$ of forced vital capacity (FEF25-75\%) were expressed as Z-scores [32]. Spirometry was considered to be normal if both FEV1 and FEF25-75\% were $>-1.64 \mathrm{z}$-scores [33].

\section{Data analysis}

Sample size calculation was based on a baseline mean \pm SD Scond of $0.01 \pm 0.01$ from 20 healthy school-aged children measured using the same setup [28]. A sample size of 22 children in each group would provide $90 \%$ power to detect differences in washout parameter of one population standard deviation between the index and healthy control groups, at a two-sided 5\% significance level.

Continuous variables were compared using the t-test after verification for normal distribution. Categorical variables were compared using the Chi-squared test. Upper limit of normal (ULN) for lung function parameters was defined as mean+1.64 SD [33] of a healthy reference population for spirometry [32] and from our term-born controls for washout parameters.

We assessed the relationships between washout parameters and perinatal factors and other lung function parameters in univariable and multivariable regression analysis. The multivariable model was adjusted for body length, sex and gestational age. All analyses were performed using Stata statistical software (release 11; StataCorp LP, College Station, TX, USA).

\section{Results}

\section{Study population}

A total of 86 former preterm and 49 term-born children were enrolled. At least two valid $\mathrm{N}_{2} \mathrm{MBW}$ measurements were obtained in 77 (90\%) preterm and 46 (94\%) term-born participants. Reasons for exclusion were leaks, irregular breathing pattern and FRC variability $>10 \%$ for two valid trials or $>25 \%$ for three valid trials. The mean (range) age of the 77 (42 males) former preterm subjects was 9.5 (7.212.8) years and of the 46 (21 males) term-born subjects was 9.9 (6.0-15.9) years. Excluded children did not differ from those included in terms of age, sex, weight, length or gestational age (data not shown).

Preterm and term-born children showed similar characteristics at inclusion (table 1). Preterm participants had a mean (range) gestational age of 28.7 (23.9-34.7) weeks and mean (range) birth weight of 1139 (4202980) g. $75 \%$ of them developed BPD and $21 \%$ fulfilled the criteria for current asthma at school age. The characteristics of the preterm participants in relation to their gestational age (ELGAN and no-ELGAN) are presented in table 2 . 
TABLE 1 Population characteristics at inclusion

\begin{tabular}{lccc} 
& Control & Preterm & p-value ${ }^{\#}$ control versus preterm \\
\hline Subjects (male) $\mathbf{n}(\mathbf{n})$ & $46(21)$ & $77(42)$ & 0.34 \\
Age years & $9.9 \pm 3.6$ & $9.5 \pm 1.5$ & 0.37 \\
Height $\mathbf{~ m ~}$ & $138.9 \pm 19.2$ & $134.8 \pm 9.3$ & 0.12 \\
Weight $\mathbf{~ k g}$ & $34.1 \pm 12.8$ & $30.1 \pm 7.6$ & 0.06 \\
BMI $\mathbf{~ g} \cdot \mathbf{m}^{-2}$ & $17.0 \pm 2.3$ & $16.7 \pm 2.6$ & 0.52
\end{tabular}

Data are presented as mean $\pm \mathrm{SD}$, unless otherwise stated. BMI: body mass index. ${ }^{\#}$ : t-test or Chi-squared test, as appropriate.

\section{Nitrogen multiple-breath washout}

In addition, 14 preterm and eight term-born children were excluded from Scond analysis, and seven preterm and nine term-born children were excluded from Sacin analysis due to insufficient SIII values left after breath quality control as specified by the current consensus [25]. Children excluded for invalid Scond and Sacin did not differ from those included in terms of age, sex, weight, length or gestational age (data not shown).

LCI and $\mathrm{M}_{2} / \mathrm{M}_{0}$ showed no significant difference between preterm and term-born children (table 3, fig. 1). The moment ratio $\mathrm{M}_{1} / \mathrm{M}_{0}$ was significantly higher in preterm children (mean difference $0.49 \mathrm{z}$-scores, $95 \%$ CI $0.05-0.92 ; \mathrm{p}=0.028$ ) (table 3), with $11(14 \%)$ out of 77 preterm children showing $\mathrm{M}_{1} / \mathrm{M}_{0}$ values $>\mathrm{ULN}$. While Sacin did not differ between preterm and term-born participants (fig. 2), Scond was significantly higher in former preterm compared to term-born children (mean difference $1.74 \mathrm{z}$-scores, 95\% CI 1.17-2.30; p<0.001) (fig. 3). 34 (54\%) out of 63 preterm children had Scond values $>$ ULN. Scond remained significantly elevated $(\mathrm{p}<0.001)$ in subgroups of preterm children without respiratory symptoms, current asthma, atopic sensitisation or without any of those three criteria (data not shown). Additionally, in preterm children with normal spirometry, Scond was significantly elevated. Results remained similar for raw Scond and Sacin values without tidal volume correction (data not shown). In preterm children, Scond showed no significant difference between ELGAN and no-ELGAN (table 3), while it was slightly elevated in preterm children with BPD compared to preterm children without BPD (mean difference 0.008, 95\% CI

TABLE 2 Characteristics of former preterm children, according to extremely low gestational age

\begin{tabular}{|c|c|c|c|}
\hline & $\begin{array}{c}\text { ELGAN }<28 \text { weeks } \\
\text { of gestation }\end{array}$ & $\begin{array}{c}\text { No-ELGAN } \geqslant 28 \text { weeks } \\
\text { of gestation }\end{array}$ & p-value ${ }^{\#}$ \\
\hline Subjects (male) n (n) & $38(21)$ & $39(21)$ & 0.90 \\
\hline \multicolumn{4}{|l|}{ Perinatal characteristics } \\
\hline Gestational age weeks & $26.7 \pm 1.1$ & $30.7 \pm 1.9$ & $<0.001$ \\
\hline Birth weight kg & $0.87 \pm 0.22$ & $1.39 \pm 0.54$ & $<0.001$ \\
\hline ELBW & $28(74)$ & $8(21)$ & $<0.001$ \\
\hline Antenatal steroids & $33(87)$ & $32(82)$ & 0.56 \\
\hline Surfactant & $17(45)$ & $14(36)$ & 0.43 \\
\hline Respiratory support ${ }^{\Uparrow}$ days & $45(30-54)$ & $8(7-23)$ & $<0.001^{\# \#}$ \\
\hline Intubation days & $1(0-4)$ & $0(0-3)$ & $0.11^{\# \#}$ \\
\hline Supplementary oxygen days & $72(54-86)$ & $32(4-47)$ & $<0.001^{\# \#}$ \\
\hline BPD & 37 (97) & $21(54)$ & $<0.001$ \\
\hline Chorioamnionitis $^{+}$ & $21(55)$ & $10(26)$ & 0.007 \\
\hline Maternal smoking during pregnancy & $4(11)$ & $2(5)$ & 0.38 \\
\hline \multicolumn{4}{|l|}{ Characteristics at school age } \\
\hline Age years & $9.8 \pm 1.8$ & $9.2 \pm 1.2$ & 0.11 \\
\hline Height $\mathrm{cm}$ & $136.1 \pm 10.4$ & $133.6 \pm 8.1$ & 0.24 \\
\hline Weight kg & $31.1 \pm 8.6$ & $30.1 \pm 6.5$ & 0.56 \\
\hline $\mathrm{BMI} \mathrm{kg} \cdot \mathrm{m}^{-2}$ & $16.6 \pm 2.7$ & $16.7 \pm 2.5$ & 0.78 \\
\hline Positive skin-prick testing ${ }^{\S . f}$ & $12(32)$ & $7(18)$ & 0.17 \\
\hline
\end{tabular}

Data are presented as mean $\pm \mathrm{SD}, \mathrm{n}(\%)$ or median (interquartile range), unless otherwise stated. ELGAN: extremely low gestational age neonates; ELBW: extremely low birth weight $(<1.0 \mathrm{~kg})$; BPD: bronchopulmonary dysplasia; BMI: body mass index. \#: t-test, nonparametric Wilcoxon rank sum test (\#\#) or Chi-squared test as appropriate, comparing ELGAN with no-ELGAN; ${ }^{\text {? }}$ : days of invasive and noninvasive ventilation; ${ }^{+}$: missing data in the ELGAN subgroup $(n=1)$ and in the no-ELGAN subgroup $(n=1)$; ${ }^{\S}$ : positive on at least one of the tested common inhalant allergens; ${ }^{f}$ : missing data in the ELGAN subgroup ( $\mathrm{n}=1$ ). 
TABLE 3 Lung function values in former preterm and in term-born children

\begin{tabular}{|c|c|c|c|c|c|c|}
\hline & \multirow[t]{2}{*}{ Control } & \multicolumn{3}{|c|}{ Preterm } & \multicolumn{2}{|c|}{ Mean difference $(95 \% \mathrm{CI})$} \\
\hline & & All & $\begin{array}{c}<28 \text { weeks of } \\
\text { gestation }\end{array}$ & $\begin{array}{c}\geqslant 28 \text { weeks of } \\
\text { gestation }\end{array}$ & $\begin{array}{c}\text { Preterm } \\
\text { versus control }\end{array}$ & $\begin{array}{c}\text { ELGAN versus } \\
\text { no-ELGAN }\end{array}$ \\
\hline $\mathrm{N}_{2} \mathrm{MBW}$ & 46 & 77 & 38 & 39 & & \\
\hline Scond & 38 & 63 & 31 & 32 & & \\
\hline Sacin & 37 & 70 & 36 & 34 & & \\
\hline$M_{1} / M_{0}$ & $1.57 \pm 0.10$ & $1.62 \pm 0.13$ & $1.60 \pm 0.12$ & $1.64 \pm 0.13$ & $0.05(0.01-0.09)^{*}$ & $-0.05(-0.10-0.01)$ \\
\hline$M_{2} / M_{0}$ & $4.96 \pm 0.69$ & $5.27 \pm 0.93$ & $5.10 \pm 0.80$ & $5.43 \pm 1.03$ & $0.309(-0.005-0.623)$ & $-0.33(-0.75-0.09)$ \\
\hline Scond & $0.017 \pm 0.008$ & $0.031 \pm 0.012$ & $0.033 \pm 0.011$ & $0.029 \pm 0.014$ & $0.014(0.009-0.018)^{* * *}$ & $0.003(-0.003-0.010)$ \\
\hline Sacin & $0.067 \pm 0.029$ & $0.069 \pm 0.034$ & $0.070 \pm 0.038$ & $0.068 \pm 0.030$ & $0.001(-0.012-0.014)$ & $0.002(-0.014-0.018)$ \\
\hline $\mathrm{FRC} \mathbf{m L} \cdot \mathrm{kg}^{-1}$ & $44.9 \pm 8.1$ & $46.2 \pm 11.2$ & $48.1 \pm 10.4$ & $44.4 \pm 11.8$ & $1.3(-2.5-0.5)$ & $3.7(-1.3-8.8)$ \\
\hline Minute ventilation $\mathrm{mL} \cdot \mathrm{kg}^{-1}$ & $254.4 \pm 92.8$ & $263.6 \pm 80.0$ & $263.5 \pm 79.8$ & $263.8 \pm 81.2$ & $9.2(-22.2-40.6)$ & $-0.3(-36.9-36.3)$ \\
\hline$V_{0} \mathbf{m L} \cdot \mathbf{k g}^{-1}$ & $3.41 \pm 0.70$ & $3.37 \pm 0.64$ & $3.35 \pm 0.59$ & $3.39 \pm 0.69$ & $-0.04(-0.28-0.20)$ & $-0.04(-0.33-0.25)$ \\
\hline $\mathrm{FeNO}^{\#} \mathrm{ppb}$ & & $13.5 \pm 19.2$ & $13.9 \pm 18.6$ & $13.1 \pm 20.1$ & & $0.8(-8.1-9.6)$ \\
\hline $\mathrm{FeNO}^{\#} \geqslant 20 \mathrm{ppb}$ & & $9(12)$ & $4(11)$ & $5(13)$ & & \\
\hline
\end{tabular}

Data are presented as $\mathrm{n}$, mean \pm SD or $\mathrm{n}(\%)$, unless otherwise stated. ELGAN: extremely low gestational age neonates (<28 weeks of gestation); $\mathrm{N}_{2}$ MBW: nitrogen multiple-breath washout; LCl: lung clearance index; FRC: functional residual capacity (from $\mathrm{N}_{2} M B W$ ); VD: airway dead space volume; FEV1: forced expiratory volume in $1 \mathrm{~s}$; FVC: forced vital capacity; FEF25-75\%: forced expiratory flow at 25-75\% of FVC; FeN0: exhaled nitric oxide fraction. ${ }^{\#}$ : missing data for FeNo measurement $(n=1)$ in the no-ELGAN subgroup. *: $p<0.05$; $^{* * *}$ : $p<0.001$, using t-test.

0.001-0.015; $\mathrm{p}=0.026$ ). However, after adjustment for gestational age, the difference between BPD and no BPD disappeared.

FRC, minute ventilation and $V \mathrm{D}$, all corrected for body weight, showed no difference between preterm and term-born children, nor between ELGAN and no-ELGAN (table 3).

\section{Spirometry}

We found some evidence for airway obstruction: mean \pm SD FEV1 was $-0.60 \pm 1.11 \mathrm{z}$-score in former preterm children (table 3 ), of which $18 \%$ (14 out of 77 ) had decreased values $(<-1.64 \mathrm{z}$-score) [32].

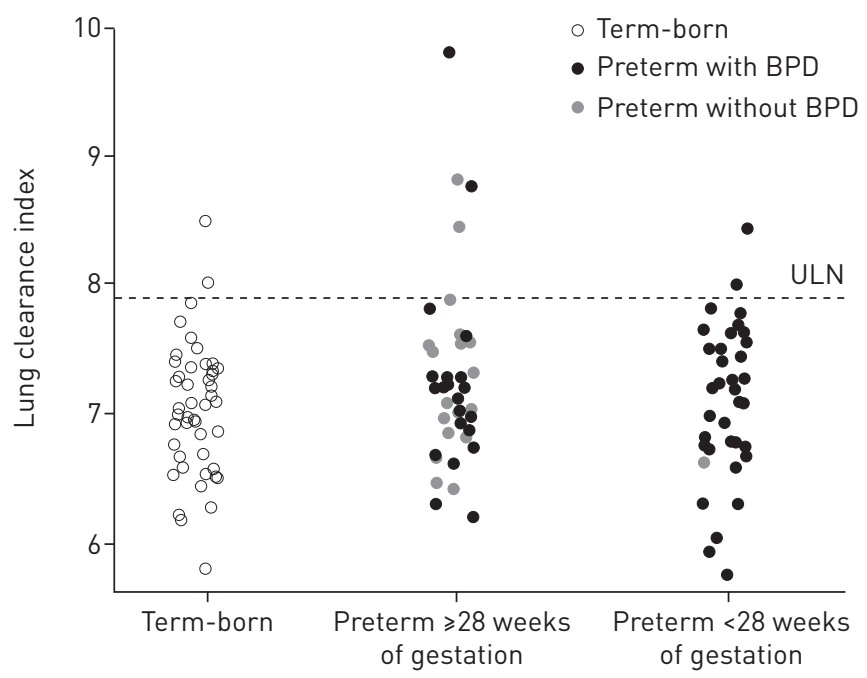

FIGURE 1 Lung clearance index (LCI) of nitrogen multiple-breath washout measurement in 46 term-born children, 39 preterm children born $\geqslant 28$ weeks of gestation and 38 preterm children born <28 weeks of gestation. Of the five preterm children with LCI greater than the upper limit of normal (ULN), four had current asthma, respiratory symptoms and/or abnormal spirometry. BPD: bronchopulmonary dysplasia. 


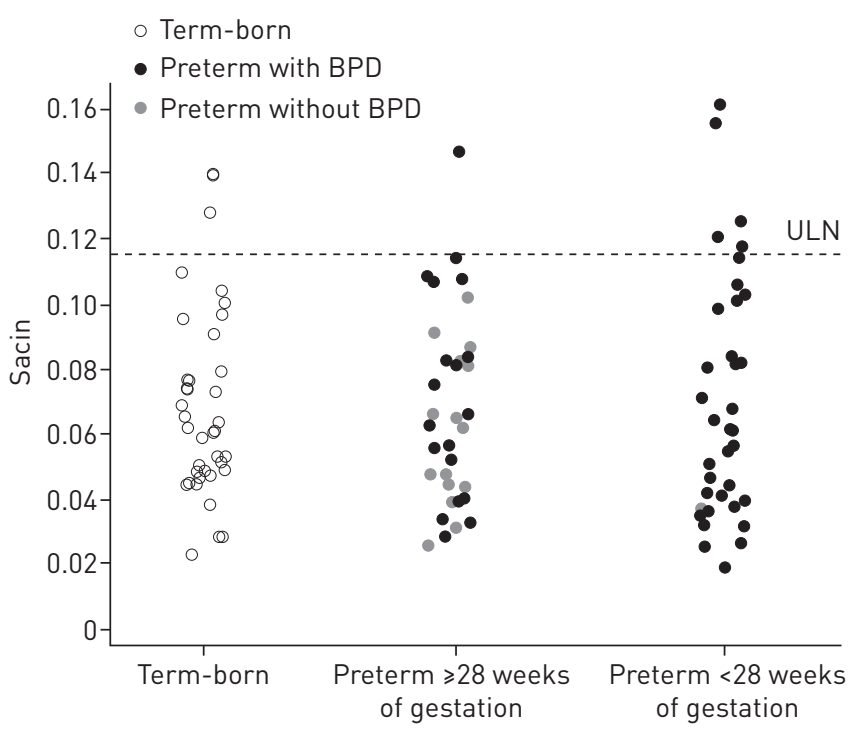

FIGURE 2 Sacin of nitrogen multiple-breath washout measurement in 37 term-born children, in 34 preterm children born $\geqslant 28$ weeks of gestation and in 36 preterm children born <28 weeks of gestation. BPD: bronchopulmonary dysplasia; ULN: upper limit of normal.

Mean \pm SD FEF25-75\% was $-0.97 \pm 1.20$ z-score (table 3), of which $30 \%$ (23 out of 77 ) had decreased values. There was no significant difference in FEV1 and FEF25-75\% between ELGAN and no-ELGAN (table 3), nor between preterm children with and without BPD.

\section{Factors associated with elevated Scond}

Regression analysis in the whole study population showed that from all significantly associated perinatal factors with Scond in the univariable model (gestational age, BPD, days of supplementary oxygen, respiratory support, intubation, surfactant and antenatal steroids) only gestational age remained significantly associated in the multivariable model after adjustment for gestational age, body length and sex $\left(\mathrm{r}^{2} 37 \%\right)$ (table 4$)$. When stratifying for ELGAN within the group of preterm children, the relationship between Scond and gestational age remained significant within the ELGAN group $(-0.004,95 \%$ CI $-0.008-0.001 ; \mathrm{p}=0.010)$, while it was not significant in the no-ELGAN group. For Sacin and spirometry (FEV1 and $\mathrm{FEF} 25-75 \%)$ no perinatal factor was significantly associated (data not shown). Including lung function parameters as exposure variables (Sacin, LCI, $V \mathrm{D} \cdot \mathrm{kg}^{-1}, \mathrm{FRC} \cdot \mathrm{kg}^{-1}$, minute ventilation $\cdot \mathrm{kg}^{-1}, \mathrm{FEV} 1$

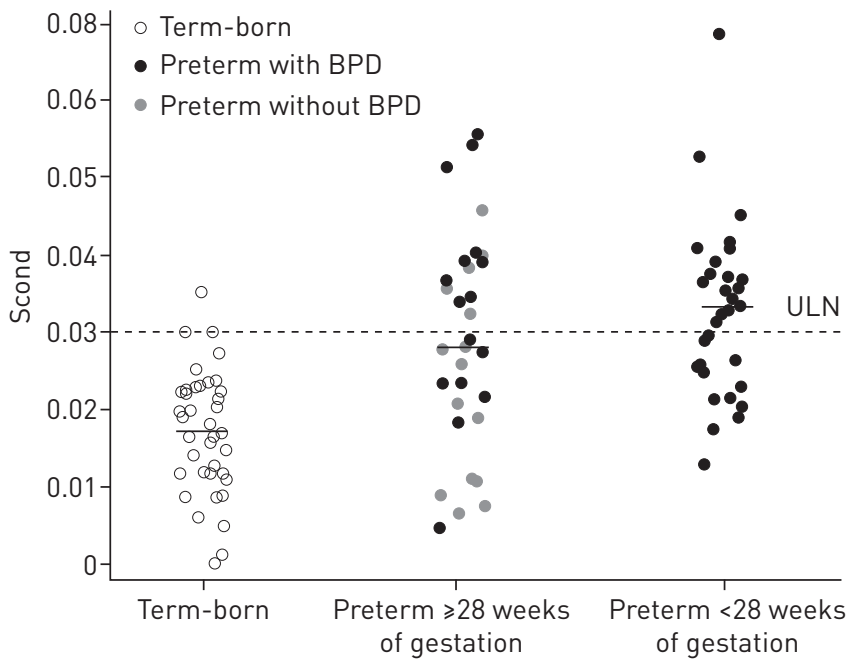

FIGURE 3 Scond in former preterm and term-born children. Scond of nitrogen multiple-breath washout measurement in 38 term-born children, in 32 preterm children born $\geqslant 28$ weeks of gestation and in 31 preterm children born < 28 weeks of gestation with mean Scond values per group. BPD: bronchopulmonary dysplasia; ULN: upper limit of normal. 
TABLE 4 Perinatal factors associated with Scond

\begin{tabular}{|c|c|c|c|c|c|c|}
\hline & \multicolumn{3}{|c|}{ Univariable model } & \multicolumn{3}{|c|}{ Multivariable model ${ }^{\#}$} \\
\hline & B & $95 \% \mathrm{Cl}$ & p-value & B & $95 \% \mathrm{Cl}$ & p-value \\
\hline Gestational age weeks & -0.001 & $-0.002--0.001$ & $<0.001$ & -0.001 & $-0.002--0.001$ & $<0.001$ \\
\hline No-ELGAN/ELGAN & 0.010 & $0.005-0.015$ & $<0.001$ & 0.010 & $0.005-0.015$ & $<0.001$ \\
\hline BPD absent/present & 0.013 & $0.009-0.018$ & $<0.001$ & 0.005 & $-0.003-0.013$ & 0.26 \\
\hline Supplementary oxygen days & 0.0001 & $0.0001-0.0002$ & $<0.001$ & 0.0001 & $0.0001-0.0001$ & 0.072 \\
\hline Respiratory support days & 0.0003 & $0.0002-0.0004$ & $<0.001$ & -0.0001 & $-0.0002-0.0001$ & 0.50 \\
\hline Intubation days & 0.0003 & $0.0001-0.0007$ & 0.049 & 0.0001 & $-0.0003-0.0003$ & 0.89 \\
\hline Surfactant no/yes & 0.012 & $0.006-0.017$ & $<0.001$ & 0.003 & $-0.003-0.009$ & 0.30 \\
\hline Antenatal steroids no/yes & 0.010 & $0.005-0.015$ & $<0.001$ & -0.005 & $-0.012-0.002$ & 0.18 \\
\hline
\end{tabular}

Univariable and multivariable regression models for Scond. The only remaining significantly associated perinatal factor with Scond in the multivariable model was gestational age $\left(r^{2} 37 \%\right)$ and extremely low gestational age neonates (ELGAN) ( $\left.r^{2} 20 \%\right)$. BPD: bronchopulmonary dysplasia. \#: adjusted for gestational age, body length and sex.

and FEF25-75\%), only minute ventilation per unit of body weight showed a significant positive association with elevated Scond in the uni- and multivariable model (data not shown).

\section{Discussion}

This study is the first to specifically examine the lung function of peripheral airways in former preterm children at school age using the MBW technique. LCI reflecting global ventilation inhomogeneity did not differ between term-born and former preterm participants, including ELGAN and those with BPD. In contrast to our hypothesis, we found no evidence of diffusion-dependent ventilation inhomogeneity at the acinar level, reflected by similar Sacin values between our study groups. However, Scond was elevated in more than half of preterm participants, indicating ventilation inhomogeneity in the more proximal convection-dependent airways. Gestational age was the strongest predictor of Scond in our cohort, independent of other confounders, but in a rather weak association. These findings provide evidence for a functionally normal alveolar compartment in former preterm children at school age, albeit with disturbed airway function at a more proximal level, in the small convection-dependent airways.

Previous reports on lung function of former preterm children have provided evidence of airway obstruction [9-13], air trapping [10,12,13] and reduced diffusing capacity of the lung for carbon monoxide $[10,12,13]$. However, only one study has assessed global ventilation distribution in school-aged children born extremely preterm [10]. Although those investigators reported that $58 \%$ of those children had mildly elevated LCI, spirometry performed better in discriminating prematurity or BPD. More specific markers of peripheral ventilation inhomogeneity, such as Sacin and Scond were not assessed. In contrast to LuM et al. [10], we found no relevant difference in LCI between former preterm and term-born children, while only $6 \%$ of our prematurely-born participants had elevated LCI. This difference may be attributed to the inclusion of children born solely $<26$ weeks of gestation in their study, with a high asthma prevalence of $55 \%$ [10].

As specific regional ventilation parameters, Scond and Sacin have been shown to reflect different disease-characteristic pathogenetic mechanisms, such as in cystic fibrosis [19], asthma [18] and bronchiolitis obliterans [20]. Our results showed a distinguished pattern of regional ventilation inhomogeneity in former preterm children: we found normal Sacin values indicating normal ventilation distribution at the acinar level. Thus, our study provides evidence for a functionally normal alveolar compartment in former preterm children. In contrast, Scond was consistently elevated in more than half of preterm participants without asthma symptoms or other lung function abnormalities, indicating impaired ventilation distribution in the more proximal conducting airways. Multivariable regression analysis confirmed the association between Scond and prematurity, showing that gestational age could explain $37 \%$ of the variability in Scond independent of other confounders. Lack of association in the multivariable model between other perinatal factors such as BPD, days of supplementary oxygen and intubation with Scond or spirometry after adjusting for gestational age underlines the pathophysiology of new BPD [34]: functional changes are not primarily caused by the therapy (barotrauma or oxygen toxicity), but rather by prematurity per se. However, it remains difficult to disentangle the exact influence of the different interrelating factors, mostly because gestational age and BPD showed strongly collinear effects within our observational study. There was no clear difference for Scond between ELGAN and 
no-ELGAN within preterm children. Furthermore, the association between Scond and gestational age in weeks was strongest within the ELGAN group. Thus, the pathophysiology of the premature lung is complex, with many factors contributing and interacting. Whether the association of minute ventilation with Scond indicates an adaptive mechanism upon increased Scond, or a primary regulatory response cannot be answered by our data [15]. The mechanism for this pattern of ventilation inhomogeneity could be explained by the fact that these children were born during the late canalicular-early saccular period of lung development, when the peripheral conducting airways are already developed and thus vulnerable, while the alveolar regions develop later and continue to grow after birth [35]. Thus, our findings indicate a mismatch in the growth of peripheral conducting airways and lung parenchyma in children born preterm, supporting the concept of a "dysanaptic" lung growth [36,37], related to prematurity.

Overall there was no evidence for increased global ventilation inhomogeneity in preterm children. While LCI and $\mathrm{M}_{2} / \mathrm{M}_{0}$ showed no difference between preterm and term-born children, $\mathrm{M}_{1} / \mathrm{M}_{0}$ was elevated in 11 children. Since the weight given to the latter part of the washout increases from $M_{1} / M_{0}$ to $M_{2} / M_{0}$ a more proximal involvement of peripheral airways could be postulated.

Recent advances in imaging techniques [38] and stereological counting methods [35] have provided new evidence for continued alveolarisation beyond infancy up to young adulthood in the healthy lung. Of particular interest, a recent study using helium magnetic resonance showed evidence of continued alveolarisation at school age both in healthy adolescent [38] and former preterm children [39], half the latter diagnosed with BPD. Given that the main pathophysiological feature of the new BPD was described as "arrest" of alveolar development [6], these findings suggest that the time frame in which alveolarisation and potential lung repair occur may be much wider than previously thought. It is unclear whether the morphological term of continued alveolarisation can be used in an equivalent and sensible way to describe lung function. Nevertheless, our study provides evidence for a functionally intact continued alveolarisation in former preterm children, and is thus in line with the structural findings. However, our cross-sectional data cannot answer the question of the exact underlying mechanism or structural correlate of this complex process.

The main limitation of our study is the model-based interpretation of Sacin and Scond and thus the lack of proof for its association with specific lung morphology. Therefore, the interpretation of our results strongly depends on the assumption that Scond and Sacin are valid proxies for the regional ventilation distribution in convection- and diffusion-convection-dependent lung zones, respectively [18-20]. A further limitation is the lack of spirometry in term-born controls and thus the limited comparison to reference values only [32]. The lack of precise birthweight records in term-born controls hampered adjustment for birthweight in the regression models. However, in analysis limited to preterm children, birthweight showed no significant association to Scond. Concerning the group of preterms, we mainly included very preterm born children. This might represent a selection bias towards children with a higher frequency of respiratory sequelae. Age distribution in term-born and preterm children was not equal, with a greater proportion of older children among the term-born group. However, average age was similar and since results remained stable after adjustment for age, the influence seems negligible. Finally, although present, the effect size of gestational age on Scond was relatively weak. The rather small sample size of the subgroups of our study has to be considered when interpreting the associations between perinatal factors and convection-dependent ventilation inhomogeneity. Some of the extremely preterm-born participants also had normal Scond values despite low gestational age. Presumably, there are additional factors (e.g. genetic, epigenetic and environmental exposures) that may influence the susceptibility of the immature lung and determine the long-term outcome of pulmonary injury.

In conclusion, our study provides first evidence for a functionally normal alveolar compartment in former preterm children at school age, but impaired ventilation inhomogeneity of conducting airways, a pattern supporting a prematurity-related dysanaptic lung growth. Future studies need to elaborate the exact relationship between peripheral lung function and the underlying structural deficit, and thus help to advance prophylactic and therapeutic strategies in prematurely-born infants.

\section{Acknowledgements}

The authors would like to thank all children and their families for their participation in the study. We express our gratitude to Sandra Luescher, Carmen Casaulta, Monika Graf, Linda Beul-Béguin, Gisela Wirz and Sharon Schmid (University Children's Hospital Bern, Bern, Switzerland) for their valuable work and support.

\section{References}

1 Blencowe H, Cousens S, Oestergaard MZ, et al. National, regional, and worldwide estimates of preterm birth rates in the year 2010 with time trends since 1990 for selected countries: a systematic analysis and implications. Lancet 2012; 379: 2162-2172.

2 Field DJ, Dorling JS, Manktelow BN, et al. Survival of extremely premature babies in a geographically defined population: prospective cohort study of 1994-9 compared with 2000-5. BMJ 2008; 336: 1221-1223. 
3 Stoll BJ, Hansen NI, Bell EF, et al. Neonatal outcomes of extremely preterm infants from the NICHD Neonata Research Network. Pediatrics 2010; 126: 443-456.

4 Jobe AH. What is BPD in 2012 and what will BPD become? Early Hum Dev 2012; 88: Suppl. 2, S27-S28.

5 Northway WH Jr, Rosan RC, Porter DY. Pulmonary disease following respirator therapy of hyaline-membrane disease. Bronchopulmonary dysplasia. N Engl J Med 1967; 276: 357-368.

Baraldi E, Filippone M. Chronic lung disease after premature birth. N Engl J Med 2007; 357: 1946-1955.

Jobe AH, Bancalari E. Bronchopulmonary dysplasia. Am J Respir Crit Care Med 2001; 163: 1723-1729.

8 Berkelhamer SK, Mestan KK, Steinhorn RH. Pulmonary hypertension in bronchopulmonary dysplasia. Semin Perinatol 2013; 37: 124-131.

9 Fawke J, Lum S, Kirkby J, et al. Lung function and respiratory symptoms at 11 years in children born extremely preterm: the EPICure study. Am J Respir Crit Care Med 2010; 182: 237-245.

10 Lum S, Kirkby J, Welsh L, et al. Nature and severity of lung function abnormalities in extremely pre-term children at 11 years of age. Eur Respir J 2011; 37: 1199-1207.

11 Hacking DF, Gibson AM, Robertson C, et al. Respiratory function at age 8-9 after extremely low birthweight or preterm birth in Victoria in 1997. Pediatr Pulmonol 2013; 48: 449-455.

12 Kaplan E, Bar-Yishay E, Prais D, et al. Encouraging pulmonary outcome for surviving, neurologically intact, extremely premature infants in the postsurfactant era. Chest 2012; 142: 725-733.

13 Joshi S, Powell T, Watkins WJ, et al. Exercise-induced bronchoconstriction in school-aged children who had chronic lung disease in infancy. J Pediatr 2013; 162: 813-818.

14 Hülskamp G, Lum S, Stocks J, et al. Association of prematurity, lung disease and body size with lung volume and ventilation inhomogeneity in unsedated neonates: a multicentre study. Thorax 2009; 64: 240-245.

15 Latzin P, Roth S, Thamrin C, et al. Lung volume, breathing pattern and ventilation inhomogeneity in preterm and term infants. PLoS One 2009; 4: e4635.

16 Weibel ER. It takes more than cells to make a good lung. Am J Respir Crit Care Med 2013; 187: 342-346.

17 Burri PH. Structural aspects of postnatal lung development - alveolar formation and growth. Biol Neonate 2006; 89: 313-322.

18 Verbanck S, Schuermans D, Paiva M, et al. Nonreversible conductive airway ventilation heterogeneity in mild asthma. J Appl Physiol 2003; 94: 1380-1386.

19 Horsley AR, Macleod KA, Robson AG, et al. Effects of cystic fibrosis lung disease on gas mixing indices derived from alveolar slope analysis. Respir Physiol Neurobiol 2008; 162: 197-203.

20 Thompson BR, Hodgson YM, Kotsimbos T, et al. Bronchiolitis obliterans syndrome leads to a functional deterioration of the acinus post lung transplant. Thorax 2014; 69: 487-488.

21 Stanojevic S, Jensen R, Sundaralingam D, et al. Alternative outcomes for the multiple breath washout in children with CF. J Cyst Fibros 2015; 14: 490-496.

22 Pramana IA, Latzin P, Schlapbach LJ, et al. Respiratory symptoms in preterm infants: burden of disease in the first year of life. Eur J Med Res 2011; 16: 223-230.

23 Asher MI, Keil U, Anderson HR, et al. International Study of Asthma and Allergies in Childhood (ISAAC): rationale and methods. Eur Respir J 1995; 8: 483-491.

24 Dweik RA, Boggs PB, Erzurum SC, et al. An official ATS clinical practice guideline: interpretation of exhaled nitric oxide levels $\left(F \mathrm{E}_{\mathrm{NO}}\right)$ for clinical applications. Am J Respir Crit Care Med 2011; 184: 602-615.

25 Robinson PD, Latzin P, Verbanck S, et al. Consensus statement for inert gas washout measurement using multiple- and single-breath tests. Eur Respir J 2013; 41: 507-522.

26 Singer F, Houltz B, Latzin P, et al. A realistic validation study of a new nitrogen multiple-breath washout system. PLoS One 2012; 7: e36083.

27 Singer F, Kieninger E, Abbas C, et al. Practicability of nitrogen multiple-breath washout measurements in a pediatric cystic fibrosis outpatient setting. Pediatr Pulmonol 2013; 48: 739-746.

28 Bigler A, Yammine S, Singer F, et al. Feasibility of automated slope III and Scond analysis in children. Pediatr Pulmonol 2015; 50: 805-813.

29 Aurora P, Kozlowska W, Stocks J. Gas mixing efficiency from birth to adulthood measured by multiple-breath washout. Respir Physiol Neurobiol 2005; 148: 125-139.

30 Fowler WS. Lung function studies: the respiratory dead space. Am J Physiol 1948; 154: 405-416.

31 Miller MR, Hankinson J, Brusasco V, et al. Standardisation of spirometry. Eur Respir J 2005; 26: 319-338.

32 Stanojevic S, Wade A, Cole TJ, et al. Spirometry centile charts for young Caucasian children: the Asthma UK Collaborative Initiative. Am J Respir Crit Care Med 2009; 180: 547-552.

33 Quanjer PH, Stanojevic S, Cole TJ, et al. Multi-ethnic reference values for spirometry for the 3-95-yr age range: the global lung function 2012 equations. Eur Respir J 2012; 40: 1324-1343.

34 Proietti E, Riedel T, Fuchs $\mathrm{O}$, et al. Can infant lung function predict respiratory morbidity during the first year of life in preterm infants? Eur Respir J 2014; 43: 1642-1651.

35 Herring MJ, Putney LF, Wyatt G, et al. Growth of alveoli during postnatal development in humans based on stereological estimation. Am J Physiol Lung Cell Mol Physiol 2014; 307: L338-L344.

36 Green M, Mead J, Turner JM. Variability of maximum expiratory flow-volume curves. J Appl Physiol 1974; 37: $67-74$

37 Merkus PJ, Borsboom GJ, Van Pelt W, et al. Growth of airways and air spaces in teenagers is related to sex but not to symptoms. J Appl Physiol 1993; 75: 2045-2053.

38 Narayanan M, Owers-Bradley J, Beardsmore CS, et al. Alveolarization continues during childhood and adolescence: new evidence from helium-3 magnetic resonance. Am J Respir Crit Care Med 2012; 185: 186-191.

39 Narayanan M, Beardsmore CS, Owers-Bradley J, et al. Catch-up alveolarization in ex-preterm children: evidence from ${ }^{3} \mathrm{He}$ magnetic resonance. Am J Respir Crit Care Med 2013; 187: 1104-1109. 